\title{
The Ring-Opening Polymerization of D,L-Lactide in the Melt Initiated with Tetraphenyltin
}

\author{
F. E. KOHN, ${ }^{*}$ J. W. A. VAN DEN BERG, G. VAN DE RIDDER, and \\ J. FEIJEN, Department of Chemical Technology, Polymer Division, \\ Twente University of Technology, P.O. Box 217, 7500 AE, Enschede, \\ The Netherlands
}

\begin{abstract}
Synopsis
Melt polymerization conditions for D,L-lactide initiated with tetraphenyltin were studied with regard to polymer molecular weight and weight distributions. "Single" polymerization, "multiple" polymerization (four or eight reactions at the same time), and time-dependent studies are described. Single polymerizations using constant initiator concentrations resulted in a broad scattering of nonreproducible molecular weight values. Multiple polymerizations at constant initiator concentrations, however, resulted in nearly identical molecular weight profiles. Multiple polymerizations at different initiator concentrations did not show an inverse dependency of initiator concentration on polymer molecular weight. Both the single and multiple melt polymerizations resulted in rather broad molecular weight distributions. The presence of hydrolysis products of lactide during the melt polymerization most likely has a detrimental effect on molecular weight. After a short induction period the rather slow polymerization of D,L-lactide resulted in a maximal molecular weight followed by a slight decrease in molecular weight to a constant value. It is concluded that the polymerization of D,L-lactide in the melt initiated with tetraphenyltin does not proceed through a "living" mechanism.
\end{abstract}

\section{INTRODUCTION}

Over the past 20 years there have been studies for the application of poly(D,L-lactic acid) as a biodegradable polyester in medicine and surgery, ${ }_{1}^{1}$ e.g., as sutures, ${ }^{2}$ burn wound covering, ${ }^{3}$ sustained release system, ${ }^{4}$ or as resorbable prostheses in maxillofacial ${ }^{5}$ and orthopedic surgery. ${ }^{6}$ In our laboratories we have applied poly(D,L-lactic acid) as temporary eardrum grafts in rats $^{7}$ and dogs.

Although poly(D,L-lactic acid) may be prepared by the direct condensation of $\mathrm{L}(+)$ - and $\mathrm{D}(-)$-lactic acid, ${ }^{8-10}$ the preferred method for the preparation of high molecular weight poly(D,L-lactic acid) is the ring-opening polymerization of the six-membered cyclic diester D,L-lactide $\left(\mathrm{mp} 126^{\circ} \mathrm{C}\right)$, initiated with a suitable initiator, e.g., tin-(IV)-chloride, ${ }^{11} \mathrm{Zn},{ }^{12}$ stannous octoate, ${ }^{5}$ or tetraphenyltin. The polymerization can be performed in solution under mild conditions ${ }^{13}$ or, for the preparation of high molecular weight polymers, preferably in the melt at higher temperatures. Purified D,L-lactide (mp $126^{\circ} \mathrm{C}$ ), derived from the racemic mixture of $\mathrm{L}(+)$ - and $\mathrm{D}(-)$-lactic acid, is the molecular 1:1 compound of both enantiomers $L(-)$-lactide and $D(+)$ lactide. ${ }^{14}$

'Present address: First b.v., P.O. Box 45, 3900 AA Veenendael, The Netherlands.

Journal of Applied Polymer Science, Vol. 29, 4265-4277 (1984)

(c) 1984 John Wiley \& Sons, Inc.

CCC 0021-8995/84/124265-13\$04.00 
It has been reported that for the melt polymerization of lactide the polymer molecular weight can be controlled by varying the amount of initiator. ${ }^{15,16}$ This statement, however, is not in agreement with other literature data. ${ }^{3,17-21}$ A literature survey on the melt or bulk polymerization of lactide and of other six- and seven-membered ring lactones, i.e., glycolide and $\epsilon$ caprolactone, revealed that initiators have been employed in a wide concentration range and also that both high and low molecular weights have been obtained with no relationship to initiator concentrations..$^{19,22-36}$ Only under solution polymerization conditions does the ring-opening polymerization proceed in a predictable way. ${ }^{37}$

The purpose of this study is to find the relation between melt polymerization conditions for D,L-lactide initiated with tetraphenyltin and polymer molecular weight and weight distribution. In addition to this, the existence of a "living" mechanism for the melt polymerization of D,L-lactide is discussed.

\section{EXPERIMENTAL}

\section{Materials}

D,L-Lactic Acid [a 90\% aqueous solution containing the racemic mixture of $\mathrm{L}(+)$-lactic acid and $\mathrm{D}(-)$-lactic acid] and tetraphenyltin were purchased from Polysciences.

D,L-Lactide ( $\mathrm{mp} 126^{\circ} \mathrm{C}$ ) was prepared according to the procedures of Kulkarni et al. ${ }^{15,38}$ and of Sinclair and Gynn ${ }^{29}$ using zinc oxide as the depolymerization catalyst. Water, solvent, and part of the condensation water were stripped off for $14-16 \mathrm{~h}$ at $110-140^{\circ} \mathrm{C}$ pot temperature, starting at 760 $\mathrm{mm} \mathrm{Hg}$ and stepwise decreasing to about $25 \mathrm{~mm} \mathrm{Hg}$. The temperature of the bath was then increased to $180^{\circ} \mathrm{C}$ and the crude D,L-lactide was distilled at $0.1 \mathrm{~mm} \mathrm{Hg}$ for about $4 \mathrm{~h}$. The crude D,L-lactide was recrystallized several times in order to remove the meso-lactide $\left(\mathrm{mp} 43^{\circ} \mathrm{C}\right) .{ }^{14}$ Approximately $5 \mathrm{~mL}$

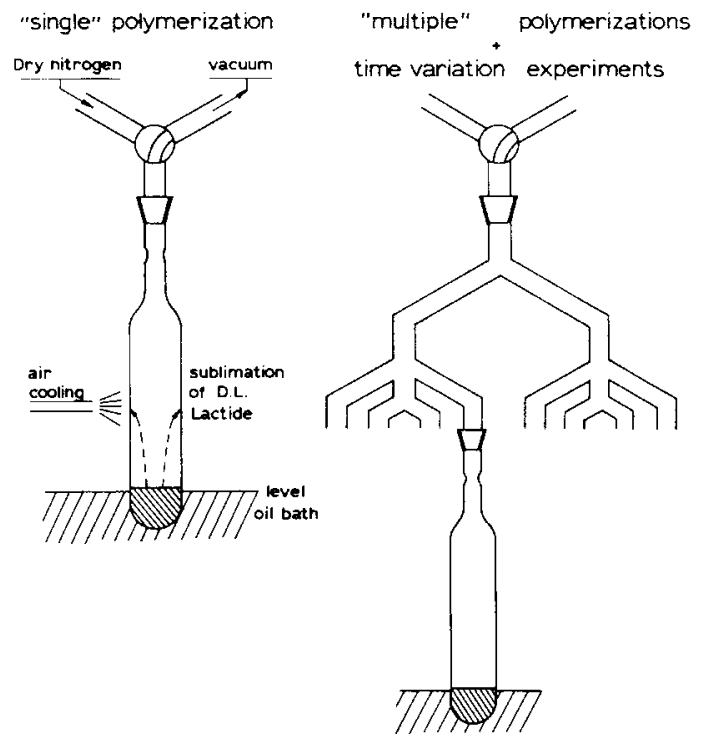

Fig. 1. Experimental set up for single and multiple melt polymerization. 
of ethyl acetate was used for every $20 \mathrm{~g}$ of crude $\mathrm{D}, \mathrm{L}$-lactide ${ }^{39}$ and the first recrystallization was carried out in the presence of charcoal. Purified D,Llactide (yield $15-20 \%$; $\mathrm{mp} 126^{\circ} \mathrm{C}$ ) was dried in a vacuum oven at room temperature in order to prevent sublimation, stored in a desiccator over $\mathrm{P}_{2} \mathrm{O}_{5}$ and subsequently over $\mathrm{CaCl}_{2}$. Prior to use a small column (length 5$10 \mathrm{~cm}$; diameter $0.5 \mathrm{~cm}$ ) containing D,L-lactide was eluted with a small amount of ice-cold dry ether to remove residual impurities.

Poly(D,L-Lactic Acid). The ring-opening polymerization of D,L-lactide in the melt was also based on the procedures developed by Kulkarni et al. ${ }^{15,38}$ and Sinclair and Gynn ${ }^{29}$ using tetraphenyltin as the initiator. Pure D,Llactide ( $1 \mathrm{~g})$ was placed in a clean polymerization tube which was dried for $24 \mathrm{~h}$. The appropriate amount of initiator dissolved in $0.5 \mathrm{~mL}$ of dry benzene was added. The tube was then connected directly (single polymerizations) or via an adaptor (multiple polymerizations) to a purge valve system with access to vacuum or dry nitrogen (Fig. 1). The solvent was evaporated at reduced pressure and the lower part of the tube was placed in an oil bath (temperature range $60-100^{\circ} \mathrm{C}$ ). D,L-lactide was sublimed onto the air cooled portion of the tube $(0.1 \mathrm{~mm} \mathrm{Hg})$ for removal of residual solvent and water vapor. A negligible amount of $\mathrm{D}, \mathrm{L}$-lactide is lost during the sublimation step. During the sublimation step the tube was purged several times with dry nitrogen. After the sublimation the tube was sealed under vacuum and next the tube was immersed in an oil bath which was kept at $180 \pm 1^{\circ} \mathrm{C}$ for 24 $\mathrm{h}$ or for various time periods, respectively. Apart from the "time variation" experiments, the resulting poly(D,L-lactic acid) (glass transition $51-59^{\circ} \mathrm{C}$ according to DSC) was dissolved in acetone, precipitated in water under vigorous stirring, filtered, and dried in vacuo at room temperature. Only very small amounts of monomer are removed by this procedure. For "time variation" experiments four or eight sealed tubes (cf. multiple polymerization) were immersed in the oil bath of $180 \pm 1^{\circ} \mathrm{C}$ at time $t=0$. At predetermined intervals the tubes were removed and quenched by cooling. After storage at $-15^{\circ} \mathrm{C}$ the contents of the tubes were dissolved in tetrahydrofuran. Aliquots of these solutions were used for gel permeation chromatography (see below). Two peaks were observed in the chromatogram if D,L-lactide monomer was still present. Conversion of D,L-lactide was calculated from the relative peak area's (after correction for the difference in refractive index increments of polymer in THF $(d n / d c=0.050)$ and of D,L-lactide in THF $(d n / d c=0.046)$, respectively). $\bar{M}_{n}$ and $\bar{M}_{w}$ of the polymers were also calculated. This procedure differs from the one described by Gilding and Reed ${ }^{19}$ and by Sanina et al., ${ }^{33}$ in which residual monomer was removed and the percentage conversion was based on the amount of insoluble polymer obtained.

\section{METHODS}

\section{Gel Permeation Chromatography}

The gel permeation chromatographic measurements were performed with a low-pressure Water's Model GPC-200 apparatus having a 5-mL syphon. Four analytical columns $(4 \mathrm{ft}$ long $\times 0.375 \mathrm{in}$.) packed with Styragels of porosity ratings $10^{5}, 3 \times 10^{4}, 10^{3}$, and $250 \AA$ had been installed in series. The operational conditions were: flow rate, $1 \mathrm{~mL} / \mathrm{min}$; solvent, THF; tem- 
perature, $30^{\circ} \mathrm{C}$; sample concentration, approximately $0.5 \%$; sample injection time, $60 \mathrm{~s}$. A differential flow through refractometer was used as a detector. The columns were calibrated by the $Q$-factor method ${ }^{40}$ with poly(D,L-lactic acid) samples of known $\bar{M}_{n}$ and $\bar{M}_{w}$ values, previously determined by membrane osmometry and light scattering, respectively. $Q$, the molecular weight/ $\AA$ was shown to be $33 \pm 1$ when based on the $\bar{M}_{w}$ values of the poly(D,L-lactic acid) samples determined by light scattering. $Q$ values based on osmometrically determined $\bar{M}_{n}$ values turned out to be higher (58 \pm 5 ). In another study, ${ }^{41}$ using a universal calibration curve procedure, we were able to decide that $Q=33 \pm 1$ had to be taken as the right value. In the present study, columns with a low exclusion limit in the low molecular weight region were chosen to be able to determine monomer and oligomer content in a reliable way.

Empirical peak-broadening correction was applied based on polystyrenes for which $\bar{M}_{n}, \overline{\mathrm{M}}_{w}$, and $\bar{M}_{z}$ were known (membrane osmometry, light scattering, and equilibrium distribution in the ultracentrifuge, respectively ${ }^{42}$ ).

\section{Light Scattering Measurements}

Light scattering measurements were performed at five concentrations below $0.5 \%(\mathrm{w} / \mathrm{v})$ in a Fica 50 light scattering photometer, using vertically polarized light of wave length $436 \mathrm{~nm}$. Reliable Zimm plots were obtained for acetone solutions which had been filtered through Fluoropore $0.2 \mu \mathrm{m}$ filters (purchased from Millipore Corp.). Toluene could not be used as a solvent because of the very low $d n / d c$ value [ -0.02 for poly(D,L-lactic acid) in toluene]. Light scattering measurements were performed at 11 angles between $30^{\circ}$ and $150^{\circ}$ to the incident beam. Refractive index increments were measured on a Brice Phoenix refractometer. The $d n / d c$ value for poly(D,L-lactic acid) in acetone at $25^{\circ} \mathrm{C}$ was 0.097 .

\section{Membrane Osmometry}

A Hallikkainen Model 1361 Automatic Osmometer was used with cellophane membranes (Sartorius Membrane Filter SM 11539). Measurements at five concentrations were carried out in toluene as the solvent.

\section{RESULTS}

\section{Single Melt Polymerization}

In Table I the results of 20 "single" melt polymerizations of D,L-lactide initiated with tetraphenyltin are presented. Apart from the initiator concentrations, the conditions for these polymerizations were identical. Several polymerizations resulted in very low polymer molecular weights ("failures"). Only one of these values, the first result at $M / I=30,000$, is included in Table I.

All polymerizations resulted in broad molecular weight distributions. GPC chromatograms showed that the smallest molecules had molecular weights in the range 100-3000 (DP $=1-20$ ). The largest molecules present ranged from 65,000 to $140,000(\mathrm{DP}=450-970$ ) for the low molecular weight samples up to $665,000-1.450,000$ (DP $=4600-10,000$ ) for the medium and high molecular weight samples. 
TABLE I

Results of Single Melt Polymerizations of D,L-Lactide ${ }^{a}$

\begin{tabular}{rrrr}
\hline $\begin{array}{c}\text { Monomer/initiator } \\
\text { (mol/mol) }\end{array}$ & $\overline{\boldsymbol{M}}_{w}$ & $\overline{\boldsymbol{M}}_{n}$ & $\overline{\boldsymbol{M}}_{w} / \overline{\boldsymbol{M}}_{n}$ \\
\hline 3750 & 11,000 & 2000 & 5.5 \\
3750 & 85,000 & 20,000 & 4.2 \\
7500 & 13,000 & 2000 & 6.5 \\
7500 & 14,000 & 2000 & 7.0 \\
7500 & 14,000 & 2000 & 7.0 \\
7500 & 118,000 & 31,000 & 3.8 \\
15,000 & 15,000 & 4000 & 3.7 \\
15,000 & 36,000 & 12,000 & 3.0 \\
15,000 & 36,000 & 14,000 & 2.6 \\
15,000 & 78,000 & 18,000 & 4.3 \\
15,000 & 111,000 & 44,000 & 2.5 \\
15,000 & 117,000 & 30,000 & 3.9 \\
15,000 & 125,000 & 59,000 & 2.1 \\
15,000 & 128,000 & 47,000 & 2.7 \\
15,000 & 166,000 & 39,000 & 4.2 \\
15,000 & 183,000 & 38,000 & 4.8 \\
30,000 & 5000 & 1000 & 5.0 \\
30,000 & 20,000 & 11,000 & 1.8 \\
30,000 & 90,000 & 49,000 & 1.8 \\
30,000 & 179,000 & 48,000 & 3.7 \\
\hline
\end{tabular}

a Initiator tetraphenyltin; polymerization time $24 \mathrm{~h}$; polymerization temperature $180^{\circ} \mathrm{C}$.

\section{Multiple Melt Polymerizations}

In the following sets of melt polymerizations the adaptor described in Experimental (Fig. 1) was used, and four tubes were prepared for polymerization at the same time. In the first three series $(1,2$, and 3$)$ the monomer/initiator ratio was kept constant at $7500,15,000$, and $30,000 \mathrm{~mol} /$ mol, respectively. The results are presented in Table II. The molecular weight distributions of the poly(D,L-lactic acid) samples prepared in this way were rather similar to those observed during the single polymerization study. Always a long "tail" towards very low molecular weight species (6501500) was observed, whereas at the same time chain molecules having molecular weights of $310,000-665,000$ were present. In the next three series of multiple polymerizations $(4,5$, and 6$)$ the initiator concentration was varied in each series. The results are presented in Table III. In series 6 the initiator concentrations were kept very low.

\section{Effects of Impurities}

In one set of multiple (four at a time) melt polymerizations, either a small amount of water, of recrystallization solvent (ethyl acetate), or of the ethyl acetate mother liquor was added along with D,L-lactide plus initiator. The fourth tube without extra additions served as a reference. After sublimation the tubes were sealed and polymerized in the usual manner. These results are presented in series 7 of Table IV. In another set of multiple polymerizations two tubes had been filled with freshly prepared D,Llactide whereas the other two tubes contained D,L-lactide which had been stored in a desiccator over $\mathrm{P}_{2} \mathrm{O}_{5}$ and subsequently $\mathrm{CaCl}_{2}$ for several months.The results are given in series 8 of Table IV. 
TABLE II

Results of Multiple Melt Polymerizations of D,L-Lactide at Constant Initiator Concentrations ${ }^{\mathrm{a}}$

\begin{tabular}{ccc}
\hline $\bar{M}_{w}$ & $\bar{M}_{n}$ & $\bar{M}_{w} / \bar{M}_{n}$ \\
\hline & Series $1: \mathrm{M} / \mathrm{I}=7500$ & \\
65,000 & 29,000 & 2.2 \\
67,000 & 20,000 & 3.3 \\
68,000 & 34,000 & 2.0 \\
70,000 & 27,000 & 2.6 \\
& Series $2: \mathrm{M} / \mathrm{I}=15,000$ & 3.0 \\
54,000 & 18,000 & 2.9 \\
58,000 & 20,000 & 2.6 \\
58,000 & 22,000 & 2.9 \\
59,000 & 20,000 & \\
& Series $3: \mathrm{M} / \mathrm{I}=30,000$ & 2.8 \\
88,000 & 31,000 & 3.0 \\
91,000 & 30,000 & 2.4 \\
103,000 & 43,000 & 3.0 \\
127,000 & 43,000 & 1800 \\
\hline
\end{tabular}

a Initiator, tetraphenyltin; polymerization time, $24 \mathrm{~h}$; polymerization temperature, $180^{\circ} \mathrm{C}$.

\section{Time Variation Experiments}

Several multiple polymerizations were carried out to determine the effect of polymerization time on the degree of conversion of D,L-lactide and on polymer molecular weight. A representative "reaction profile" is shown in Figure 2 leading to $\bar{M}_{w}=104,000$ and $\bar{M}_{n}=43,000$ after $24 \mathrm{~h}$ of polymerization, using a monomer/initiator ratio of $30,000 \mathrm{~mol} / \mathrm{mol}$. After a short induction period (see below) there appear to be three stages of polymerization. During the first 8-9 h a comparatively rapid rise of $\bar{M}_{w}$ and $\bar{M}_{n}$ was

TABLE III

Results of Multiple Melt Polymerizations of D,L-Lactide at Varying Initiator Concentrations ${ }^{\mathrm{a}}$

\begin{tabular}{cccc}
\hline$M / I$ & $\bar{M}_{w}$ & $\bar{M}_{n}$ & $\bar{M}_{w} / \bar{M}_{n}$ \\
\hline \multicolumn{4}{c}{ Series 4} \\
15,000 & 27,000 & 5300 & 5.1 \\
30,000 & 38,000 & 11,000 & 3.5 \\
No initiator & 100,000 & 42,000 & 2.4 \\
& 6100 & 1000 & 6.1 \\
7500 & Series 5 & & \\
15,000 & 39,000 & 19,000 & 2.1 \\
30,000 & 129,000 & 42,000 & 3.1 \\
& 63,000 & 28,000 & 2.2 \\
30,000 & Series 6 & & \\
60,000 & 69,000 & 18,000 & 3.8 \\
90,000 & 55,000 & 13,000 & 4.2 \\
180,000 & 53,000 & 19,000 & 2.8 \\
& 46,000 & 23,000 & 2.0 \\
\hline
\end{tabular}

anitiator, tetraphenyltin; polymerization time, $24 \mathrm{~h}$; polymerization temperature, $180^{\circ} \mathrm{C}$. 
TABLE IV

Results of Multiple Melt Polymerizations of D,L-Lactide plus Deliberately Added Impurities (Series 7); Old and Freshly Prepared D,L-Lactide (Series 8) ${ }^{\mathrm{a}}$

\begin{tabular}{lrcc} 
& $\bar{M}_{w}$ & $\bar{M}_{n}$ & $\bar{M}_{w} / \bar{M}_{n}$ \\
\hline Initiator only & Series $7: \mathrm{I} / \mathrm{M}=15,000$ & \\
I + $\mathrm{H}_{2} \mathrm{O}$ & 30,000 & 9000 & 3.3 \\
I + ethyl acetate & 28,000 & 4500 & 6.2 \\
I + ethyl acetate & 51,000 & 9000 & 5.7 \\
mother liquor & & & \\
& 6200 & 525 & 11.8 \\
Old D,L-lactide & Series $8: \mathrm{I} / \mathrm{M}=15,000$ & & 3.1 \\
Old D,L-lactide & 11,500 & 3700 & 4.6 \\
Fresh D,L-lactide & 15,500 & 3400 & 2.7 \\
Fresh D,L-lactide & 116,000 & 43,000 & 3.2 \\
\hline
\end{tabular}

${ }^{a}$ Initiator, tetraphenyltin; polymerization time, $24 \mathrm{~h}$; polymerization temperature, $180^{\circ} \mathrm{C}$.

observed. In the same period conversion of D,L-lactide mounted up to 80 $90 \%$, this conversion being rather slow during the first $3 \mathrm{~h}$. Second, after $9 \mathrm{~h}$ the increase of $\bar{M}_{w}$ and $\bar{M}_{n}$ levelled off, reaching a maximum after about $15 \mathrm{~h}$. At this stage conversion of D,L-lactide was approximately $95 \%$. In the next hours a slow decrease of $\bar{M}_{w}$ and $\bar{M}_{n}$ was observed, levelling off to constant values after $20-22 \mathrm{~h}$, as was also established by a few multiple polymerizations of long duration. Total conversion of $\mathrm{D}, \mathrm{L}$-lactide remained almost constant (95-96\%) at this time.

During the first $6.5-9 \mathrm{~h}$ of polymerization, polymer molecular chains continued to grow as is indicated by Table $\mathrm{V}$, showing molecular weight values of the largest chain molecules present as a function of polymerization time. A number of independent short-time multiple polymerizations were carried out to study more closely the induction period preceeding the actual start of the polymerization.

A representative short-time "reaction profile" $(M / I=15,000)$ is given in Figure 3. After 30 min hardly any polymer was formed which was typical

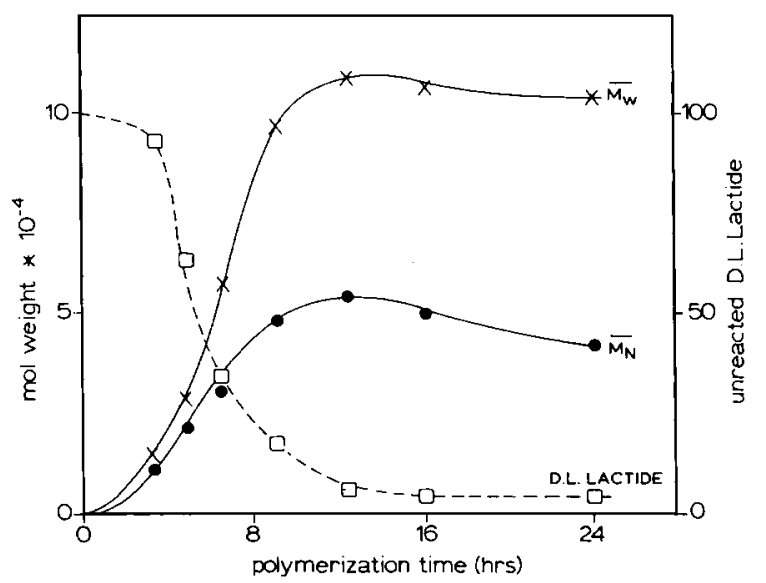

Fig. 2. Reaction profile for a 24 -h melt polymerization of D,L-lactide initiated with tetraphenyltin $\left(T=180^{\circ} \mathrm{C} ; \mathrm{M} / \mathrm{I}=30,000\right)$. 
TABLE V

Molecular Weight Values of Largest Chain Molecules Present during Time Variation Experiment of Figure $2^{a}$

\begin{tabular}{cc}
$\begin{array}{c}\text { Polymerization time } \\
(\mathrm{h})\end{array}$ & $\begin{array}{c}\text { MW of largest chain molecules } \\
\left(\times 10^{-4}\right)\end{array}$ \\
\hline 3.5 & 6.5 \\
5 & 9.5 \\
6.5 & 31 \\
9 & 66 \\
12 & 66 \\
16 & 150 \\
24 & 66 \\
\hline
\end{tabular}

for this polymerization. Table VI shows molecular weight values of the largest chain molecules present in the early stages of polymerization.

\section{DISCUSSION}

\section{Optimization of Polymerization}

Our early observation that high molecular weight poly(D,L-lactic acid) could not be prepared reproducibly by melt polymerizing D,L-lactide initiated with tetraphenyltin was confirmed by the results of the single melt polymerization study shown in Table I. However, better results are obtained if four polymerizations are carried out simultaneously. In the first two series of four melt polymerizations at constant initiator concentrations (series 1 and 2, Table II) a very good reproducibility was found for $\bar{M}_{w}$ and to a somewhat lesser extent for $\bar{M}_{n}$. Also, in series 3 , at the lowest initiator concentration, the reproducibility is still satisfactory.

In the next three series of multiple melt polymerizations (series $4,5,6$, Table III) the initiator concentration was varied in each series, but no inverse relationship between initiator concentration and polymer molecular weight was obtained. In series 6 the four different initiator concentrations

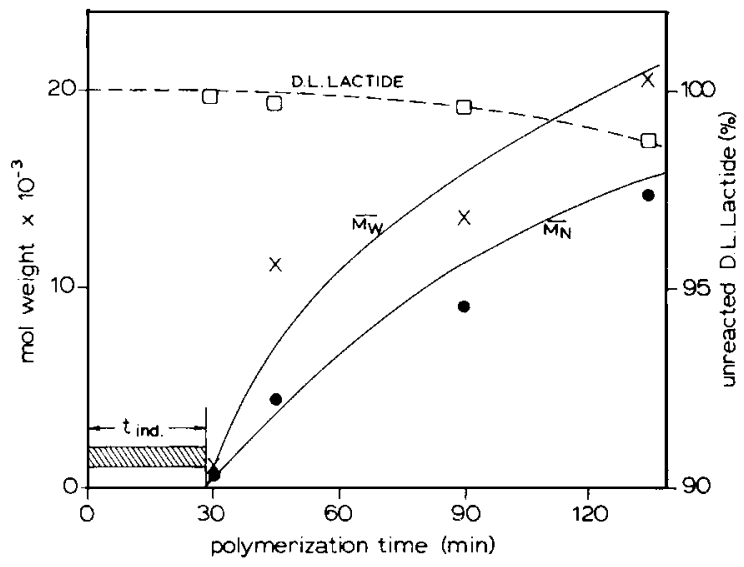

Fig. 3. Short-time reaction profile for a melt polymerization of $\mathrm{D}, \mathrm{L}$-lactide initiated with tetraphenyltin $\left(T=180^{\circ} \mathrm{C} ; \mathrm{M} / \mathrm{I}=15,000\right)$. 
TABLE VI

Molecular Weight Values of Largest Chain Molecules Present during Short-Time Time Variation Experiment of Figure 3

\begin{tabular}{cc}
$\begin{array}{c}\text { Polymerization time } \\
(\min )\end{array}$ & $\begin{array}{c}\text { MW of largest chain molecules } \\
\left(\times 10^{-3}\right)\end{array}$ \\
\hline 30 & 1.4 \\
45 & 30.4 \\
90 & 66 \\
135 & 66 \\
\hline
\end{tabular}

were kept quite low. In this case only a slight decrease of polymer molecular weight with decreasing initiator concentration was observed. This might suggest that without initiator still poly(D,L-lactic acid) with reasonably high polymer molecular weight can be obtained. This suggestion, however, is contradicted by the last result of series 4 of Table III.

The reproducibility of lactone polymerizations has received little attention so far. A substantial variation of $\bar{M}_{w}$ between 57,000 and 98,000 was observed by Lundberg et al. ${ }^{35}$ during solution polymerization of $\epsilon$-caprolactone. It was suggested that this variation was due to the presence of trace amounts of moisture which was confirmed by a very significant decrease of polymer molecular weight after polymerization in the presence of 1.5 mol \% of $\mathrm{H}_{2} \mathrm{O}$. According to Fouty, ${ }^{23}$ water can act as a chain transfer agent. During our experiments, much care was taken to exclude impurities. Elution of the small column of D,L-lactide with ice-cold, dry ether resulted according to spectroscopic analysis in the removal of small amounts of low molecular weight poly(D,L-lactic acid) and, most probably, of lactoyllactic acid (cf. Ref. 43) (see below). A number of experiments was carried out to study more closely the possible effects of impurities, including: (i) the establishment of the optimum depolymerization temperature; (ii) the search for better recrystallization solvents; (iii) the effect of impurities on the polymerization of D,L-lactide in the melt; (iv) the "aging" effect of D,L-lactide.

In this investigation the maximum depolymerization temperature was $180^{\circ} \mathrm{C}$ (at $0.1 \mathrm{~mm}$ ) because it was found that crude $\mathrm{D}, \mathrm{L}$-lactide formed at higher temperatures as recommended by Kulkarni et al. ${ }^{15,38}$ and Sinclair and Gynn ${ }^{29}$ could not effectively be purified by recrystallization. From a number of organic solvents, chloroform and a large excess of ether (cf. Ref. 14) turned out to be effective recrystallization solvents, in addition to ethyl acetate. However, polymers prepared from D,L-lactide recrystallized from ether or from chloroform did not have higher polymer molecular weights.

The poly(D,L-lactic acid) prepared from the D,L-lactide to which the ethyl acetate mother liquor had been added (series 7, Table IV) had a significantly lower polymer molecular weight as compared to the others. This indicates that possible contaminants to the D,L-lactide such as moisture or the recrystallization solvent are effectively removed during the sublimation step. It is believed that the ethyl acetate mother liquor formed during the recrystallization of D,L-lactide (cf. Ref. 14) may contain D,L-lactide, meso-lactide ( $\mathrm{mp} 43^{\circ} \mathrm{C}$ ), low molecular weight poly(D,L-lactic acid), and lactoyllactic acid (cf. Ref. 43). The latter compound may be formed by hydrolysis of $D, L-$ 
lactide and especially of meso-lactide, which is much more sensitive to moisture than racemic $\mathrm{D}, \mathrm{L}$-lactide. ${ }^{44} \mathrm{We}$ have found that meso-lactide can be polymerized under identical conditions as D,L-lactide, and we suggest that the detrimental effect on the polymerization of D,L-lactide in the presence of ethyl acetate mother liquor was actually caused by the presence of lactoyl lactic acid (cf. Ref. 23).

It is concluded from the results presented in series 8 of Table IV that D,L-lactide stored in a desiccator over $\mathrm{P}_{2} \mathrm{O}_{5}$ and subsequently over $\mathrm{CaCl}_{2}$ is subject to an aging effect, i.e., formation of lactoylactic acid from remnants of the moisture sensitive meso-lactide present in the D,L-lactide.

\section{Comments on the Reaction Mechanism}

The two melt polymerization reaction profiles shown in Figures 2 and 3 are representative for a number of other observed reaction profiles. Our time variation results may be compared with data on the melt polymerization of glycolide initiated with stannous octoate and lauryl alcohol as a catalyst activator at $220^{\circ} \mathrm{C}^{19}$ or with antimony trifluoride at $160-170^{\circ} \mathrm{C}$; and with data on the bulk polymerization of $\epsilon$-caprolactone. ${ }^{45}$ It then appears that under our experimental conditions the conversion of D,L-lactide was a comparatively slow process. Gilding and Reed ${ }^{19}$ observed that $80 \%$ conversion of glycolide had taken place within the first $30 \mathrm{~min}$ and an additional $3.5 \mathrm{~h}$ yielded a further $16 \%, 96 \%$ being the limit of polymerization. Polymer chains of molecular weights as large as $2 \times 10^{6}$ were present within $30 \%$ of conversion. No induction period was reported, although Sanina et al. ${ }^{33}$ monitored a relatively slow initiation process with antimony trifluoride. From a low conversion copolymerization study ${ }^{19}$ it was concluded that glycolide was clearly more reactive than lactide.

Young et al..$^{45}$ mentioned the bulk polymerization of $\epsilon$-caprolactone initiated with a coordination-insertion type initiator at $204^{\circ} \mathrm{C}$, by following the viscosity as a function of polymerization time. Although the polymerization appears to proceed much faster, the shape of the $\epsilon$-caprolactone reaction profile is comparable to the one drawn in Figure 2, also showing a maximum in polymer molecular weight; however, an induction period is not mentioned.

Recently, Hyon et al. ${ }^{46,47}$ reported a relationship between $\bar{M}_{v}$ and polymerization time for the polymerization of L-lactide. Also in this case a maximum was observed except for the polymerization of lower temperatures $\left(140^{\circ} \mathrm{C}\right)$. On the basis of these results it was suggested that significant thermal degradation occurred in the polymerization at higher temperatures. A living mechanism for the ring-opening polymerization of lactones has frequently been discussed. ${ }^{19,33,35,37,45,48}$ Thus a living mechanism was postulated by Sanina et al. ${ }^{33}$ for the melt polymerization of glycolide, whereas Gilding and Reed ${ }^{19}$ and Young et al. ${ }^{45}$ disagree with such a mechanism for the melt.polymerization of glycolide and $\epsilon$-caprolactone, respectively. Ouhadi et al. ${ }^{37}$ got strong indications that under solution polymerization conditions the polymerization of $\epsilon$-caprolactone indeed proceeded through a living mechanism. If the conditions for such a mechanism are met ${ }^{48}$ (cf. Ref. 49), the number average molecular weight can be calculated theoretically from 


\section{$\bar{M}_{n}=$ degree of polymerization $\times$ molecular weight D,L-lactide}

$$
=\frac{[\mathrm{D}, \mathrm{L} \text {-lactide }]}{[\text { tetraphenyltin }]} \times 144
$$

In addition to this, the resulting poly(D,L-lactic acid) will have a Poisson molecular weight distribution which would be indistinguishable for high molecular weight polymers from a monodisperse system with $\bar{M}_{w} / \bar{M}_{n} \approx 1$ + $1 /$ DP. Our results show clearly that theoretical $\bar{M}_{n}$ 's based on a living mechanism are very much higher than the $\bar{M}_{n}$ 's actually measured. Thus $\bar{M}_{n}$ 's varying from 4000 to 59,000 were measured for the single melt polymerizations of $\mathrm{D}, \mathrm{L}$-lactide carried out at $\mathrm{M} / \mathrm{I}=15,000$ (Table I). On the basis of a living mechanism $\bar{M}_{\mathrm{n}}=2 \times 10^{6}$ was expected. Molecular weight distributions of the various poly(D,L-lactic acid) samples prepared for this study were considerably broader than could have been expected on the basis of a living mechanism, with the exception of the $\bar{M}_{w} / \bar{M}_{n}$ values of polymers formed at the early stages of melt polymerization (see reaction profiles of Figures 2 and 3). In the latter case polymer chains were still growing (Tables $\mathrm{V}$ and VI). Both facts fit in with a living character for the early stages of melt polymerization of $\mathrm{D}, \mathrm{L}$-lactide (see, however, below). A living mechanism also implies that each tetraphenyltin molecule initiates one polymer chain. The number of initiator molecules present at the start of the polymerization can easily be calculated. The number of polymer chains after the polymerization is completed is equal to

$$
\frac{\text { wt poly(D,L-lactic acid) sample }}{\bar{M}_{n}} \times \text { Avogadro's number }
$$

From these calculations it was found that in the average the poly(D,L-lactic acid) samples having low average molecular weights, contained $400-800$ times more polymer chains than tetraphenyltin initiator molecules; those having medium average molecular weights contained 100-200 times more polymer chains; and those having high average molecular weights contained 25-80 times more polymer chains. Also in the early stages of melt polymerization (see Figs. 2 and 3) the number of polymer chains was already a multiplicity of the number of tetraphenyltin initiator molecules originally present which does not fit in with a living mechanism. These results might indicate that chain transfer phenomena ${ }_{*}$ ester interchange reactions, and perhaps the formation of cyclic compounds in a depolymerization reaction have taken place. It should be realized that in our investigation the polymerization temperature was more or less equal to the depolymerization temperature for the preparation of D,L-lactide from low molecular weight poly(D,L-lactic acid). A few polymerizations of D,L-lactide in the melt were carried out at a considerably lower reaction temperature, $130^{\circ} \mathrm{C}$, in the presence of stannous octoate as the initiator, leading to significantly higher $\bar{M}_{w}$ values but not to very high $\bar{M}_{n}$ values (e.g., $\bar{M}_{w}=326,000 ; \bar{M}_{n}=35,000$; $M / I=7000$ ). Also in these cases the number of polymer chains was found a multiplicity of the number of initiator molecules originally present (30 times more in the above example). On the other hand, it cannot be excluded 
that the tetraphenyltin molecule does not act as a real initiator, but that one tetraphenyltin molecule is able to catalyze the formation of a number of chains. Our study of the initiation mechanism of lactide ${ }^{50}$ did not give an answer as to the true initiating nature of tetraphenyltin.

\section{CONCLUSIONS}

1. Both the results of typical single and multiple melt polymerizations of $\mathrm{D}$,L-lactide indicate that polymer molecular weights cannot be predicted.

2. If multiple polymerizations are carried out at constant initiator concentration, a good reproducibility of polymer molecular weight is obtained. For multiple polymerizations carried out at different initiator concentrations an inverse dependency of initiator concentration on polymer molecular weight may not be expected.

3. The lack of reproducibility of polymer molecular weights is felt to be related to the presence of contaminants-especially hydrolysis products of D,L-lactide and meso-lactide.

4. The melt polymerization of $\mathrm{D}, \mathrm{L}-$ lactide at $180^{\circ} \mathrm{C}$ initiated with tetraphenyltin is a slow process, reaching the maximum polymer molecular weight after about $15 \mathrm{~h}$, followed by a slight molecular weight decrease to a constant value. A short induction period is noted in the reaction.

5. A living mechanism for the ring-opening polymerization of lactones has frequently been discussed. This study (molecular weight distribution, conversion, induction period) contradicts predictions that can be derived from such a living mechanism.

The authors gratefully acknowledge the contributions of Mr. H. Heuvink, Mr. S. Tuinhout, and Mr. J. M. C. Kersten to Experimental in this investigation, and Dr. D. E. Gregonis for valuable discussions.

\section{References}

1. R. L. Kronenthal, in Polymers in Medicine and Surgery, R. L. Kronenthal, Z. Oser, and E. Martin, Eds., Plenum, New York, 1975, pp. 119-137.

2. J. W. Hodge, Jr., U. S. Natl. Tech. Inform. Serv., AD Report No. 742,719, 1971.

3. J. B. Gregory, A. D. Schwope, and D. L. Wise, U. S. Natl. Tech. Inform. Serv., AD Report No. 759,381, 1973.

4. L. C. Anderson, D. L. Wise, and J. F. Howes, Contraception, 13, 375 (1976).

5. R. G. Sinclair and G. H. Gynn, U. S. Natl. Tech. Inform. Serv., AD Report No. 748,410, 1972.

6. R. K. Kulkarni, E. G. Moore, A. F., Hegyeli, and F. Leonard, J. Biomed. Mater. Res., 5, 169 (1971).

7. L. Feenstra, B. W. C. van der Ven, F. E. Kohn, and J. Feijen, Int. J. Artif. Organs, 3, 354 (1980).

8. G. T. Peckham and E. M. Filachioni, in Kirk-Othmer Encyclopedia of Chemical Technology, 2nd ed., Wiley, New York, 1967, Vol. 12, p. 170.

9. E. M. Filachioni and C. H. Fisher, Ind. Eng. Chem., 36, 223 (1944).

10. N. A. Higgins (assignor to DuPont de Nemours), U. S. Pat. 2,676,945 (1954).

11. E. Lillie and R. C. Schulz, Makromol. Chem., 176, 1901 (1975).

12. M. Vert, F. Chabot, J. Leray, and P. Christel, Makromol. Chem., Suppl. 5, 30 (1981).

13. R. C. Schulz, in Proceedings, IUPAC International Symposium Macromolecular Chemistry, Budapest, 1969, pp. 185-213.

14. G. J. van Hummel, S. Harkema, F. E. Kohn, and J. Feijen, Acta Crystallogr., B38, 1679 (1982). 
15. R. K. Kulkarni, K. C. Pani, C. Neuman, and F. Leonard, U. S. Natl. Tech. Inform. Serv., AD Report No. 636,716, 1966.

16. Assignors to Dynamit Nobel Aktiengesellschaft, Br. Pat. 932,382 (1963).

17. Th. M. Jackanicz, H. A. Nash, D. L. Wise, and J. B. Gregory, Contraception, 8, 227 (1973).

18. A. K. Schneider (assignor to Ethicon), U. S. Pat. 3,797,499 (1974).

19. D. K. Gilding and A. M. Reed, Polymer 20, 1459 (1979).

20. E. S. Nuwayser, D. L. Williams, P. M. Meier, T. C. Wu, S. F. Merchant, and J. H. Kerrigan, in Proceedings, Drug Delivery Systems, H. L. Gabelnick, Ed., DHEW Publ. No. (NIH) 77-1238, U. S. Department of Health, Education and Welfare, Washington, D. C., 1976, pp. 193-252.

21. A. Schindler and D. Harper, J. Polym. Sci., Polym. Chem. Ed., 17, 2593 (1977).

22. J. Kleine and H. H. Kleine, Makromol. Chem., 30, 23 (1959).

23. R. A. Fouty (assignor to Ethicon Inc.), Can. Pat. 808,731 (1969).

24. R. A. Fouty (assignor to Ethicon Inc.), Can. Pat. 923,245 (1973).

25. C. G. Pitt, A. R. Jeffcoat, R. A. Zweidinger, and A. Schindler, J. Biomed. Mater. Res., 13, 497 (1979).

26. D. Wasserman and Ch. C. Versfelt (assignors to Ethicon Inc.), U. S. Pat. 3, 839,297 (1974).

27. R. G. Sinclair (assignor to Gulf Oil Co.), U. S. Pat. 4,045,418 (1977).

28. B. Eling, S. Gogolewski, and A. J. Pennings, Polymer, 23, 1587 (1982).

29. R. G. Sinclair and G. H. Gynn, U. S. Natl. Tech. Inform. Serv., AD Report, No. 748,411, 1972.

30. Ch. E. Lowe (assignor to DuPont de Nemours), U. S. Pat. 2,668,162 (1954).

31. K. Chujo, H. Kobayashi, J. Suzuki, S. Tokuhara, and M. Tanabe, Makromol. Chem., 100, 262 (1967).

32. E. E. Schmitt, and R. A. Polistina (assignors to American Cyanamid), U. S. Pat. 3, 463,158 (1969).

33. G. S. Sanina, M. V. Fomina, A. K. Khomyakov, V. S. Livshits, V. A. Savin, and E. B. Lyudvig, Vysokomol. Soyed, A17, 2726 (1975) (translated into English).

34. G. L. Brode and J. V. Koleske, J. Macromol. Sci. Chem., A6, 1109 (1972).

35. R. D. Lundberg, J. V. Koleske, and K. B. Wischman, J. Polym. Sci., Part A-1, 7, 29152930 (1969).

36. E. F. Cox, F. Hostettler, and R. R. Kiser, Macromol. Syntheses, N. G. G. Gaylard, Ed., Wiley, New York, 1968, Vol. 3, pp. 111-113.

37.T. Ouhadi, Ch. Stevens, and Ph. Teyssié, Makromol. Chem., Suppl., 1, 191 (1975).

38. R. K. Kulkarni, K. C. Pani, C. Neuman, and F. Leonard, Arch. Surg., 93, 839 (1966).

39. W. R. Sorenson and T. W. Campbell, Preparative Methods of Polymer Chemistry, 2nd ed., Wiley-Interscience, New York, 1968, pp. 12-15.

40. Model 200 Gel Permeation Chromatograph Operation Manual, IM61992, Waters Associates, Inc., Milford, MA, 1974, pp. C4-C8.

41. J. A. P. P. van Dijk, J. A. M. Smit, F. E. Kohn, and J. Feijen, J. Polym. Sci., Polym. Chem. Ed., 21, 197 (1983).

42. J. W. A. van den Berg, G. van de Ridder, and C. A. Smolders, Eur. Polym. J., 17, 930 (1981).

43. C. A. Holten, A. Müller, and D. Rehbinder, Lactic Acid-Properties and Chemistry of Lactic Acid and Derivatives, Verlag Chemie, Weinheim, 1971, pp. 192-221.

44. D. D. Deane and E. G. Hammond, J. Dairy Sci., 43, 1421 (1960).

45. R. H. Young, M. Matzner, and L. A. Pilato, Am. Chem. Sci., Symp. Ser., 59, 152 (1977).

46. S. H. Hyon, K. Jamshidi, and Y. Ikada, Polym. Prepr. 24, 6-7 (1983).

47. S. H. Hyon, K. Jamshidi, Y. Ikada, and R. Kitamaru, Polym. Prepr., Jpn., 30, 329 (1981).

48. R. D. Lundberg and E. F. Cox, in Ring-Opening Polymerization, K. C. Frisch and S. L.

Reegen, Eds., Dekker, New York and London, 1969, pp. 247-302.

49. P. J. Flory, Principles of Polymer Chemistry, Cornell Univ. Press, Ithaca, NY, 1953, pp. 336-339.

50. F. E. Kohn, J. G. van Ommen, and J. Feijen, Eur. Polym. J., 19, 1081-1088 (1983).

Received December 5, 1983

Accepted March 26, 1984 